\title{
Lope Sin Pega: postvanguardismo y poesía de la resistencia*
}

\author{
Lope sin Pega: post-vanguard and subversive poetry
}

\author{
Iván Carrasco $M$.
}

Universidad Austral de Chile, Instituto de Lingüística y Literatura, Apartado postal 567, Valdivia, Chile. e-mail: icarrasc@uach.cl

\begin{abstract}
Este trabajo estudia la poesía subversiva de No se engañe nadie, no. Lope Sin Pega, compilado y prologado por Carlos Alberto Trujillo, en el marco de la literatura postvanguardista. El libro mencionado utiliza como estrategias básicas para intervenir en la lucha política contra la dictadura militar chilena la situación de clandestinidad de la autoría y de la enunciación, la máscara usada como confusión de identidades para ocultar al autor empírico y el uso de formas específicas de transtextualidad (parodia, sátira, alusiones, intertextos) para referirse al país con sus derechos abolidos entre 1973 y 1988.
\end{abstract}

Palabras clave: postvanguardismo, poesía chilena, poesía de la resistencia, máscara, transtextualidad.

This paper analyses the subversive poetry No se engañe nadie, no, Lope Sin Pega, compiled and introduced by Carlos Alberto Trujillo in the framework of post-vanguard literature. The book referred to uses the mask as a basic strategy, to intervene in the political fight against the Chilean dictatorship the clandestine situation of authorship and enunciation. The mask is used as an element of confusing identities to hide the empirical author and also the use of specific forms of transtextuality (parody, satire, allusions, intertexts) to refer to a country with its rights abolished between 1973 and 1988 .

Key words: post-vanguard, Chilean poetry, subversive poetry, mask, transtextuality.

\section{ANTECEDENTES. LA POESÍA POSTVANGUARDISTA}

La literatura postvanguardista o literatura de tradición vanguardista (Galindo 2005) está conformada por un conjunto de proyectos literarios en curso unificados por el uso extremado de ciertas figuras como la metatextualidad y la transtextualidad, de la concepción de la actividad poética como transgresión, las intensas relaciones del texto con los contextos históricos y extraverbales y de los autores empíricos y textuales con los sujetos discursivos o de la enunciación, entre otros rasgos (Galindo 2005).

En Chile, esta clase de literatura representa una continuidad y predominancia de la orientación europeizante y cosmopolita, en oposición al realismo un tanto ingenuo de la poesía testimonial de la contingencia sociopolítica y a la representación compleja y en múltiples niveles de la poesía intercultural. Aunque existen autores y obras de carácter narrativo y dramático de importancia y éxito, sin duda la poesía constituye el género dominante por su sensibilidad, rapidez y compromiso para percibir y promover los cambios socioculturales, artísticos y políticos en ambientes regionales e internacionales.

La poesía postvanguardista es un proceso complejo que se ha desarrollado en distintos niveles y aspectos, en el que es posible determinar un conjunto de categorías, problemáticas y tendencias críticas, cuestionadoras y satíricas, como la imitación paródica, el minimalismo y el neomanierismo, entre las más relevantes. La comprensión de este proceso hay que realizarla en términos dinámicos en un contexto en el cual la literatura es entendida como ampliación y ruptura de la institucionalidad literaria moderna por medio de múltiples transgresiones de la figura del sujeto autor, sobre el que se articula la tensión escritural en los márgenes de la ruptura o recuperación de su estatuto tradicional, y de nuevos mecanismos de representación de lo real. En términos sociocomunicativos supone la construcción de una nueva categoría de persona caracterizada por la opacidad comunicativa, la semiotización escindida y la fragmentación ontológica del sujeto (Galindo id.).

La relación entre escritura y realidad histórica, empírica o extratextual ha sido una preocupación permanente en las letras chilenas, desde su origen en el movimiento intelectual de 1842 hasta nuestros días, aunque en la poesía derivada del golpe de Estado del 73 la necesidad de asimilar lo sucedido, denunciar las violaciones a los derechos humanos y establecer una cultura de la resistencia al régimen militar la ha intensificado. No sólo lo hizo la poesía testimonial de la contingencia que surgió como reacción política directa, empleando sobre todo los procedimientos del realismo social, el testimonio 
político y la consigna del día, sino todas las manifestaciones líricas del período, como la neovanguardia, la etnoculturalidad, la lírica apocalíptica, que la asumieron desde diferentes estrategias escriturales para referirse o aludir de manera indirecta, oblicua, velada, figurada o autocensurada a diversos aspectos, manifestaciones o episodios de las circunstancias políticas y sociales (Carrasco 1989).

La poesía postvanguardista es un hecho relativamente heterogéneo, por lo cual se puede estudiar desde dos perspectivas al menos. Una manera de hacerlo es considerar la relación entre escritura y representación a partir de dos polos: la relación entre escritura y política y entre escritura y realidad. Galindo considera que esta discusión es posiblemente la clave del desarrollo de la vanguardia en su conflictivo entrecruzamiento con los discursos políticos e históricos, que se agudiza en el contexto de la dictadura militar. En esta situación la escritura se convierte en uno de los medios de transgresión de las pautas comunicativas dominantes, pues la reflexión sobre el estatuto del sujeto permite explorar las relaciones entre sujeto y escritura y entre escritura y realidad, además de indagar en las relaciones entre literatura y poder.

La violencia de todo orden del golpe de Estado de 1973 en Chile y la constricción de la vida ciudadana mediante la represión, el amedrentamiento y el control de todos los aspectos de la vida ciudadana pública e incluso privada que llevó a cabo el gobierno militar, provocaron inesperadas y profundas transformaciones en la sociedad, la historia, la cultura y la literatura chilenas. La mera práctica, difusión o defensa de expresiones culturales, aunque especialmente literarias por su inevitable y crítico contenido semántico, fueron consideradas actitudes, movimientos o formas de resistencia cultural al régimen militar y por ello desvalorizadas, perseguidas o implícitamente prohibidas. La reacción de los escritores opuestos al régimen ante estas amenazas de descanonización y persecución fue la de generar estrategias de resistencia política mediante sus textos, es decir, de comunicación marginal, de escritura irónica, oblicua, plural o engañosamente codificada, incluso autocensurada, para poder intervenir en la contingencia política con menores riesgos de ser perseguidos, encarcelados o exiliados.

Por supuesto, uno de los problemas fundamentales que debieron resolver los poetas fue el modo de hablar sobre la situación de dictadura, por lo tanto, la relación entre el texto poético y sus formas de representación del mundo, pero también el tipo de sujeto usado en los textos que diera pistas, apoyo y orientación al lector de la oposición, al mismo tiempo que engañara o al menos desorientara a los partidarios y guardianes del régimen.

De este modo se fue desarrollando una poesía de la resistencia, que participó de modo activo en la cotidianidad cultural e ideológica de espacios específicos del país y que hizo suyas una serie de estrategias escriturales, tales como el uso de la máscara o la identidad de personajes históricos, Lautaro o Manuel Rodríguez, la alegoría, como la del Reyno de Chile o del organismo enfermado o herido, la alusión literaria y de otras clases, los intertextos escondidos o encubiertos.

La conjetura que organiza este trabajo es que entre los textos políticos de denuncia política a la dictadura militar sobresale uno que supo elegir, coordinar y perfeccionar un conjunto de estrategias literarias de la tradición hispánica para convertirlas en estrategias de resistencia cultural a la dictadura militar en el ámbito de una poesía postvanguardista; se trata de No se engañe nadie, no. Lope Sin Pega (1999), compilado y prologado por Carlos Alberto Trujillo. Lope Sin Pega es disfraz del autor mediante el juego de ficción y realidad del autor empírico, el sujeto autorial y los variados sujetos discursivos de la parodia de textos clásicos, modernos y populares y de las alusiones y referencias a hechos, personajes y dichos históricos de la dictadura militar.

\section{RELACIONES ENTRE LOPE SIN PEGA Y CARLOS ALBERTO TRUJILLO}

Los antecedentes de este libro se pueden encontrar en Los que no vemos debajo del agua (1986), volumen poético de Carlos Alberto Trujillo, y en particular en el poema "En el papel tu nombre" de la sección "Post datas".

Luego de la introducción, que es el texto "Mis límites o fronteras personales" en que Trujillo reflexiona sobre un aspecto clave de la condición humana, sus limitaciones culturales, históricas, existenciales, personales, el texto inicial de la primera sección se titula significativamente "Bautismo". Allí el sujeto anuncia la voluntad de darse un nombre nuevo que reemplace a aquel por el que todos lo identifican, por lo tanto, renovar su identidad original, cambiarla:

"Como para empezar de nuevo

mojo mi cabeza bajo el chorro de agua

y me cambio de nombre" (p. 8). 
El resto del conjunto lírico se define como la alegoría del país bajo la dictadura militar, a veces por medio de referencias específicas al tipo de discurso predominante sobre todo en sus comienzos, que fue el "bando", documento leído para todos los habitantes del país en que se detallaban las órdenes e instrucciones que se debían cumplir para realizar el proyecto gubernamental autoritario:

"No logro escapar un momento

Del último bando

Que nos prohíbe escribir cualquier poema" (p. 21).

Otras veces se lo hace a través de alusiones, como en el poema homónimo al volumen (p. 17) o mediante relatos alegóricos, como "Tiempo de mareas", "De trenes y viajes".

En los conjuntos siguientes el estilo es más referencial, denunciatorio y de protesta, en especial en las secciones "Destos tiempos" donde, con intenso patetismo, trata el problema del hambre y la pobreza derivados de la cesantía obligada para los rivales del gobierno, como en los poemas "Para estos pies para estos miserables zapatos", "Para esta noche para todos las mañanas que se aproximan" que culmina con un apóstrofe a la divinidad "TE ROGAMOS SEÑOR" análogo al petitorio de la Misa y otros oficios católicos. Junto a este poema, también resaltan los estremecedores "ANTE ESTA OLLA VACIA" y "YO TE OFREZCO SEÑOR ESTA OLLA VACIA", en que el poeta muestra el sufrimiento y la impotencia de una familia en que el padre ha sido expulsado de su trabajo por ser de oposición y ello les provoca hambre y destrucción de expectativas.

Destacan, además, algunos poemas que tratan la problemática del cambio identitario y de nombre anunciado desde "Bautismo". En "Me escondo tras una oscura identidad" Trujillo apunta:

Me escondo tras una oscura identidad

Esperando que la lluvia

Sólo empape mi máscara diaria (p. 44)

Más adelante, en un texto muy decisivo, un sujeto representativo del autor empírico aparece enunciando un mandato bíblico y cumpliendo la misión profética de denunciar el pecado institucionalizado:

La verdad es una inquietud permanente

Una reunión prohibida una puerta $(\mathrm{x})$

Censurada un muerto en la calle DESDE HOY

Desde hoy intentaremos comunicarnos en latín

Y no debe importarnos

Ser Carlos A. Trujillo Juan Núñez Pérez

O cualquier anónimo cesante

Desde hoy seremos Tito Lucrecio Caro

Marcos Valerio Marcial -quien vivió

Entre el año 42 y el 102 de la Era Cristiana-

Total no todo ha de ser cosa de signos

Lo que hay que decir

Hay que decirlo

Y...

TU ES ILLE VIR" (p. 53).

En este texto aparecen los elementos que constituirán la base de los poemas de Lope Sin Pega: la denuncia de la dictadura militar mediante referencias a los métodos de represión, la decisión de buscar un modo de vida clandestino, lo que supone un lenguaje secreto, aquí el latín, la asunción de una "chapa", es decir, de un nombre falso para no ser descubierto, y la aceptación de esta lucha como una misión, según la cita bíblica. Además, aparece expresamente el personaje del cesante, el hombre que ha perdido o a quien se le ha quitado su trabajo y otro elemento inesperado en un texto de abierta actitud de compromiso: el juego de realidad y ficción. El texto anuncia que quienes actúan en la resistencia al gobierno militar usarán otros nombres y, a modo de ejemplo, coloca el nombre de una persona común junto a la del autor empírico del propio poema, es decir, Carlos A. Trujillo; así, pone en un mismo nivel 
de realidad a participantes del acto efectivo de la producción del texto y a otros que pueden ser imaginarios, usando también ficticiamente los nombres de escritores reales que vivieron en otra época.

Finalmente, en el poema EN EL PAPEL TU NOMBRE colocado como Post data, incluye los siguientes versos de las "Coplas a la muerte de su padre" de Jorge Manrique:

"No se engañe, nadie, no,

pensando que ha de durar

lo que espera

más que duró lo que vio,

pues que todo ha de pasar

por tal manera".

Resulta revelador que el primer verso corresponda exactamente a la primera parte del título del volumen, completado por la expresión "Lope Sin Pega" que presenta al poeta y profesor Carlos Alberto Trujillo como responsable de la compilación y del prólogo del mismo, aunque no como autor de los textos de Lope. Por otra parte, el sujeto del libro Los que no vemos debajo del agua, que simboliza la situación de Chile bajo la dictadura a través de visiones alegóricas de conjunto, se refiere a sí mismo en distintos sectores del volumen como alguien que desea cambiar su identidad por otra, que bien podría ser la de Lope Sin Pega.

Esta actitud coincide con la de muchas personas que participaron en la resistencia a la dictadura militar de Pinochet y debieron actuar en la clandestinidad para no ser sorprendidas. Por ello debían usar un nombre falso conocido sólo por sus compañeros, para que en caso de ser ubicados por los agentes de seguridad les obstaculizara o impidiera reconocer al sujeto real. Por lo demás, Carlos Alberto Trujillo tuvo experiencia personales y políticas suficientes para actuar en la contingencia en forma directa y por intermedio de su poesía debido a su militancia en la Izquierda Cristiana, uno de los partidos que luchó de distintos modos en la resistencia.

Por otra parte, Trujillo es un poeta, profesor de Castellano y $\mathrm{PhD}$ en Literatura, conocedor de las convenciones de la literatura moderna y tradicional de alta cultura, sobre todo de la poesía clásica y popular españolas, pero también del verso, las composiciones y las reglas pragmáticas de la lírica popular. Esto lo ha reconocido en más una ocasión y refiriéndose a ello en una conversación con Marcelo Coddou le contó que aun cuando en sus poemas "casi no usaba la rima, me gustaba (y me gusta) divertirme creando largos poemas rimados, más bien historias a la manera de los antiguos romances. Eso siempre me ha resultado muy fácil" (en Torres 1996: 185). Trujillo, el autor empírico, sufrió en carne propia lo que escribe, perdió "la pega", o sea, el trabajo, fue convertido en cesante por la dictadura militar, junto a otros profesores integrantes del Taller Aumen de Castro, Chiloé. Conversando con Juan Armando Epple, se ha referido a ello en relación a la creación del personaje lírico Lope Sin Pega:

J.A.E.: Claro, porque los poemas de Lope son otra historia.

C.A.T.: Sin duda. Se inscriben en esa historia de frustraciones y avatares políticos de la lucha contra la dictadura. Yo nunca he concebido la poesía como instrumento político. Pero a comienzos de los ochenta, confrontado a un panorama asfixiante de censuras y autocensuras, sentí que era necesario dar cuenta, en forma cronística, de lo que todo el mundo veía, contaba y olvidaba con la misma rapidez con que cambiaban los hechos. La historia y las pequeñas historias se hacían (u ocurrían), dolían, dejaban de doler y se olvidaban. Comencé a pensar en la necesidad de crear un heterónimo que tuviese una personalidad propia y que fuera capaz de expresar directamente esa realidad.

Chile en ese momento era un país de desempleados, con un porcentaje real muy diferente al de las cifras oficiales. /.../ el desempleado chileno bajo la dictadura ha sido en muchos casos un cesante con título universitario. Por estas razones mi heterónimo tenía que ser un personaje representativo de la sociedad chilena de estos años y para mí el cesante lo es más que ningún otro. Así que "mi otro yo" fue bautizado como Lope Sin Pega, el Fénix de los Cesantes. "Lope" porque era bueno pensar en un autor clásico, puesto que el heterónimo sería un chileno culto que iba a usar exclusivamente formas de versificación de la tradición española. "Sin Pega" porque suena muy parecido a "de Vega" y porque en Chile "sin pega" quiere decir cesante. Este heterónimo fue también un tanto premonitorio porque cuatro años después la cesantía me llegó de verdad.

El truco de escribir sólo en formas como soneto, tercetos, cuartetas, estancias, coplas de pie quebrado y la cuaderna vía, me permitía evitar todo parecido entre la poesía de Lope y la de Trujillo. Era, por lo mismo, una forma de autodefensa.

Lope por varios años hizo una vida autónoma. Nadie sabía quién se ocultaba detrás de ese nombre y, tratándose de una poesía sarcástico-burlesca que se ríe de los personajes de la "historia oficial" chilena, con referencias al dictador y todo su contingente de lacayos, habría sido muy peligroso que se descubriera al autor real /.../Y es un 
documento que da cuenta, con nombre y detalles, de toda la contingencia social del período /.../ Publicar los sonetos de Lope hoy, a veinte años del golpe de Estado, permitiría que muchos recordaran una serie de hechos que no podemos darnos el lujo de olvidar, porque los personajes todavía están allí haciendo lo suyo, como si nada hubiera pasado (Epple, en Torres 1996, pp. 209-211; la entrevista se efectuó en enero de 1988).

Además de los elementos poéticos y antecedentes analizados, la propia declaración de Trujillo deja en claro que él es el autor de Lope Sin Pega.

\section{ESTRATEGIAS POSTVANGUARDISTAS POLÍTICAS DE LOPE SIN PEGA}

Aun coincidiendo con la literatura política de oposición a la dictadura militar, Lope Sin Pega se aparta de la expresión testimonial y se acerca a la postvanguardia por el uso de procedimientos rupturistas y reescriturales.

Pienso que hay dos modos principales de oponerse literariamente a la dictadura militar chilena, así como a otros sistemas de poder. El primero, como quien habla o escribe abiertamente desde una identidad expresa, histórica, civil, sin censura ni trabas, tal como los políticos en situaciones normales o los poetas de la contingencia desde el exilio, situados en la perspectiva de un sujeto representativo de ideologías y partidos en los cuales tiene su defensa y apoyo principales.

El segundo, desde la situación interna del país, un estado de control militar, represión, censura explícita e implícita en el ámbito artístico e ideológico, amenaza militar permanente, amedrentamiento, falta de medios de toda especie, peligro. Esto provocó una literatura autocensurada, disfrazada y controlada mediante una serie de estrategias de resistencia textual contra la dictadura: la denuncia indirecta, el uso de máscaras históricas, la sátira, la parodia, la ironía y otras formas de irrisión de los detentores del poder, para debilitar su imagen. Esta modalidad conforma una poesía de la clandestinidad, es decir, una serie de textos y contextos literarios que forman parte del conjunto de actividades culturales, sociales y políticas de la oposición a un gobierno dictatorial, la que debe actuar en forma escondida, sutil, ingeniosa, para evitar ser descubierta y sustituir con ingenio e inteligencia la fuerza de las armas.

La resistencia literaria tiene algunos requerimientos básicos: poder decir lo que se desea a través de sus textos, por lo cual éstos no pueden confundirse con otros que no lo hacen (protestar, denunciar, llamar a comprometerse) ni tampoco con la condición política ni con la mera decisión u opinión del autor empírico, que también puede desarrollar tareas de agitación en forma paralela a la actividad literaria. Al mismo tiempo, hacerlo sin que se descubran los sujetos que escriben los textos, los distribuyen o comunican de diversas formas, puesto que de ello dependen no sólo su vida y su libertad, sino también la seguridad de otros y la continuidad de la lucha. También, los textos que constituyan actos de rechazo y resistencia al gobierno autoritario puedan ser comprendidos como tales, lo que significa que son textos controlados necesariamente por una voluntad ideológica; obviamente, el efecto será mayor si mantienen un nivel elevado de calidad artística porque serán leídos y aceptados con mayor facilidad.

A partir de 1973, debido a las restricciones, limitaciones y peligros de la censura y la autocensura, muchos poetas residentes en Chile debieron utilizar procedimientos mediante los cuales el verdadero mensaje apareciera disfrazado o disimulado para evitar las sanciones de los organismos oficiales. Los casos más simples fueron la publicación clandestina del libro, es decir, en ediciones reducidas e informales que circularon y fueron leídas en grupos de simpatizantes; el autor cifraba su mensaje en códigos que redujeran la cantidad de posibles intérpretes a quienes estuvieran en condiciones de hacerlo, es decir, lectores empíricos cómplices, intencionados, de los que depende la eficacia del poema. Por ello, ciertas palabras, contextos, alusiones, sólo pueden ser comprendidas por receptores determinados, chilenos o extranjeros compenetrados con la situación en referencia, lo que por otro lado es una amenaza de caducidad potencial de un amplio sector de esta poesía (Villegas 1983: 145-8).

3.1. Clandestinidad, heterogeneidad y máscara en la autoría y la enunciación. Lope Sin Pega es un nombre que nos recuerda inevitablemente a Lope de Vega, no sólo por razones de analogía fónica. Su mera denominación creaba ambigüedades que impedían saber si se trataba de un escritor chileno o extranjero, no se conocía su residencia, no se vendía su obra en librerías sino era distribuida de diferentes maneras en forma de trípticos. Según Roberto Castillo, la cualidad principal de Lope Sin Pega y de su poesía es su marginalidad, deducible a partir de su modo de difusión, precario y más o menos artesanal y que tiene varias dimensiones: su persona aparece desvinculada de su origen y su entorno, es víctima de un calculado desconocimiento de parte de Carlos Alberto Trujillo y se refleja en relación con el mundo poético convocado por sus impuestas señas de identidad (en Torres 1996: 161-62 ); según Castillo, la elección de sus intertextos principales, Quevedo, el Cid y Samaniego, es un modo de engañar a los 
agentes del régimen que deben ubicarlo y de poner en evidencia lo que no se percibe en la existencia cotidiana dominada por el ojo represor.

Esto último es discutible en parte, porque muchos ciudadanos simulaban no darse cuenta de lo que sucedía en Chile para evitarse problemas o para no hacerse visibles y ser descubiertos. Pero, de lo que no hay duda, es que desde donde estuvieran Lope Sin Pega y su autor empírico hacen una denuncia alusiva y metafórica de los problemas del país sin que fuera posible encontrar a quien echarle a culpa y castigarlo.

La marginalidad es un modo de vivir en la clandestinidad, apropiado para un escritor, pues le permite realizar su oficio sin llamar la atención, proyectar sus textos en distintos lugares sin que puedan ser detectados e incluir la clandestinidad como una estrategia no sólo de la autoría y la escritura sino también de la enunciación.

Entre los “Sonetos de Lope Sin Pega 1981-1989” destaca el primero de la sección por su carácter metatextual, por tanto, programático, se llama "Declaración de principios de Lope Sin Pega", al mismo tiempo que como reescritura paródica de la declaración de principios de la Junta Militar, que trató de autolegitimarse ideológica y jurídicamente al comienzo de su intervención:

Para pasar el rato soneteo, acortando mañanas, tardes, noches, meses y años, que no es ningún derroche, aunque más de un lector me mire feo.

\section{Para punzar heridas soneteo}

divirtiéndome igual que guagua en coche, pues mientras augustito no me roche, nada habrá de parar este tandeo.
Es deber sonetear contracorriente, contra muerte, a la mala, contra guerra, y el hacerlo es oficio de valientes.

Yo habré de sonetear que no me aterra un "empeorador" que ya se siente casi como guardado bajo tierra.

El título sugiere que el autor y enunciador de los textos llamado Lope Sin Pega es por el nombre un poeta español del Siglo de Oro y por el apellido un cesante chileno con la suficiente competencia para escribir sonetos, rasgo de por sí contradictorio en apariencia, que asimismo indica la actividad de este sujeto mediante un neologismo, "sonetear". Esta actividad remite a la función satírica de su poesía, punzar heridas, es decir, poesía cómica y crítica, lo que implica una situación negativa de la sociedad chilena que es necesario denunciar y al mismo tiempo establece la relación literatura-historia.

Entre las estrofas segunda y tercera se refiere al objeto de mofa de modo irónico, pues alude al dictador mediante un diminutivo que no significa afecto sino desprecio, "augustito", y manifiesta su condición de poeta de la resistencia que debe mantenerse oculto: "que no me roche", es decir, que no me descubra. Aunque primero ha declarado que esta actividad escritural es un "tandeo" (juego, entretención), el primer terceto la declara un "deber" cívico, un oficio de valientes, que tiene como finalidad matar simbólicamente a Pinochet según se dice de modo metafórico en el último verso.

En este soneto, Trujillo juega confundiendo la identidad del autor empírico, él mismo, con la del autor textual, Lope Sin Pega, sujeto que reúne rasgos ficticios propios de la literatura y de la figura de Lope, con otros muy reales, la cesantía que entonces era un mal característico de muchos opositores a la dictadura. En otros textos, manteniendo siempre al hablante de base, este asume la voz o identidad de otros escritores (como Lope de Vega, Luis de Góngora, Gabriela Mistral, Jorge Manrique, Garcilaso de la Vega o sujetos ficticios como Martín Fierro), de personajes históricos de la contingencia (como Pinochet, el Almirante Merino, Milton Friedman, etc.). El mismo Trujillo asume roles distintos en el volumen: compilador, prologuista, crítico, divulgador, estudioso, editor: entrega informaciones sobre la situación chilena, hace notas eruditas sobre los textos, entrega opiniones e interpretaciones variadas.

Esta estrategia de la máscara, también llamada personaje o doble, es explicada por Lastra (1987: 131-32 y ss.) como traspasos de la palabra, desdoblamientos que delatan un intento paradojal de despersonalización del hablante; este proceso sería la culminación de la instancia desrromantizadora iniciada por Charles Baudelaire, según la opinión del poeta Enrique Lihn. Trujillo la ha utilizado en los niveles de la escritura o producción textual y de la enunciación para confundir diversas identidades reales y ficticias y con ello ocultar la verdadera identidad del autor empírico de los poemas de Lope Sin Pega.

Esta misma estrategia incluye los demás niveles de la autoría y de la enunciación dando identidades determinadas y variaciones a los distintos destinatarios: a veces es un personaje indiferenciado que representa al país o a la oposición, otros son seres determinados de distinto carácter, histórico como Pinochet, o representativo de seres reales como la novia de un "Chicago boy", o imaginario de origen popular como el Viejo Pascuero.

Pero lo que no cambia es el acto poético de los conjuntos líricos, acto satírico de denuncia de los 
males del país: falta de libertad, hambre, violencia, desesperanza: "mientras aquí la olla está vacía/ y recién nos informa el Canal Nueve/ que ha ofrecido el país en garantía" (p. 38), "Diarios, radios, tevé, no muestran nada/ y la verdad es sólo un gobernante/ que merece esconderse tras su gorra" (p. 39), "Nazional esta tele, según cuentan, /.../ un hermoso país al mundo inventan" (p. 42), "Que comer es, por hoy, placer de ricos,/ fachos, pacos, marinos y milicos,/ mientras de hambre se mueren los poetas" (p. 51); "En pantalla mil bombos y bombones;/ en los pueblos hambruna y sufrimiento,/ y el ubicuo cartel: AQUI NO HAY PEGA" (48).

De este modo, la multiplicación, mixtura y confusión de agentes de la enunciación contribuyen al disimulo y al escondite del autor empírico, consolidando su situación de clandestinidad.

3.2. La transtextualidad entre el manierismo y la cultura popular. Los textos de este libro están configurados como especies de collages de citas, alusiones, referencias, notas, comentarios, observaciones, etc. que ponen en contacto la cultura literaria derivada del barroco y del manierismo hispánico con la cultura popular y pública y con la contingencia política de Chile en la década de los 80 al 90, mediante una escritura satírica, irónica, que se burla sin piedad de los errores, defectos y brutalidades de los gobernantes militares y de sus aliados: "No hay más verdad que un fracasado paro/ informóle al país el Canal Siete/ y desde Copiapó San Pinochete/ confirmó la noticia sin descaro. / Aunque para el derrumbe no hay reparo/ y el gobierno revienta como cuete/ con sus personajillos de sainete/ que viajan del poder al desamparo" (p. 44); "A diario se muestran mil jardines/ con chicos que iluminan la pantalla/ cual bellas mariposas en su enjambre/ Pero no todo es rosas y jazmines:/ el presupuesto cada mes encalla/ y su meta es cargar el IVA al hambre" (p. 54).

Las formas métricas, retóricas y estilísticas son imitaciones paródicas de la poesía clásica española, pero muchas referencias semánticas, parte del léxico, el modo irónico y ridiculizante, las alusiones históricas y geográficas forman parte de la cultura popular chilena y de la situación política de la década del 80.

La mayoría de los poemas constituyen parodias de textos manieristas, como el propio autor lo indica en su "Soneto de Lope a la manera de su coetáneo Don Luis de Góngora y Argote", engañoso porque quien ha escrito de verdad no es Lope de Vega sino Lope Sin Pega que vive en el siglo XX, por lo cual es el otro Lope el coetáneo, y en "Un soneto me mando hacer yo mismo", que usa como intertexto "Un soneto de repente", también conocido como "Un soneto me manda hacer Violante":

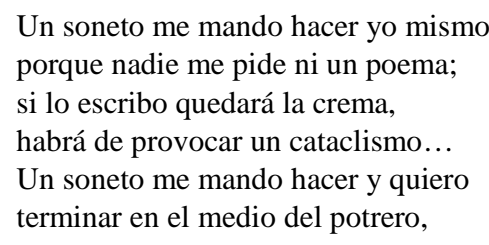

libre, como caballo de carrera, corriendo a todo dar, haciendo un ocho, pisándole la cola a don Pinocho que corre a refugiarse en su perrera

Los aspectos temáticos relevantes de origen manierista ridiculizados en los sonetos de Lope Sin Pega son el amor, la fugacidad de la vida y la relación apariencia y realidad. Entre otros destaca la "Cartasoneto de un enamorado Chicago boy a su amada en pleno período recesivo", que caricaturiza el tema amoroso: “iQué feliz, caro amor, fue la partida!/ Créditos, dólar fijo, viajes, rosas/ La pompa a todo dar, vieja tramposa/ que nos dejó sin sol y sin comida./ No muestres, ¡ay amor! Tu desconsuelo/ por este remendado y viejo traje/ que no quiere conmigo alzar el vuelo" (p. 45). Del mismo modo, se imita la fugacidad del tiempo en la "Carta desconsolada de un Chicago boy a ese pasado que se le voló en un santiamén" o la ridiculización del problema de la apariencia y la verdad del mundo, como en el "Soneto ejemplo de cómo frente a una vidriera, Lope también fue engañado por la malsana tentación", confundiendo a un maniquí, un globo que se desinfla, con una hermosa y tentadora mujer, o en otro donde escribe "La verdad enmudecen los diarios" (p. 49).

La parodia como estructura incluye ironías (como el "Humilde consejo para poner fin al constante cambio de ministros" o "Donde Lope ratifica que en verdad "Somos Millones"), juegos de palabras mediante sinonimias aparentes como "Antes cuando lucía la Lucía", "la cara puede ser cara o barata", “A Cuadra de la cuadra de Pinocho", etc., numerosas alusiones de índole histórica, personal, geográfica (como el gran marrano, Bucalemu, Sheraton, más gorila que cualquier gorila, la mamadera, el PEM, etc.). Y, por supuesto, intertextos variados que corresponden a textos, géneros y autores acreditados por una larga tradición: Lope de Vega, Góngora, Gabriela Mistral, Garcilaso de la Vega, José Hernández, Samaniego, Quevedo, Eusebio Lillo.

La situación de caos provocada por la dictadura está reproducida por un discurso postvanguardista 
fundado en la parodia, los intertextos multiplicados en forma prodigiosa, aludidos o referidos, la parodia, la ironía, usados como bases formales (modelos) de modo culto y técnico pero al mismo tiempo con finalidad satírica, todo lo cual provoca una lectura diferida e interrumpida por la necesidad del lector de resolver una enorme cantidad de diversos problemas retóricos y cognitivos para poder interpretarlo. Los textos de Lope Sin Pega guardan una apariencia doble, neomanierista y popular chilena, que divierte al lector al mismo tiempo que lo motiva y orienta políticamente, y en una ocasión usa un modelo doble como transtexto de "Miedo. Poema de Gabriela Mistral que por descuido y como un zombie, reescribió Lope", que tiene una versión anterior de Floridor Pérez.

También es destacable la conciencia expresa del proceso de producción textual por parte del autor, mediante la precisión de los títulos, p. ej. "Reflexiones ante el destrozo y cuasi exterminio de la educación chilena (que son casi una elegía)", p. 141, el uso de prólogo del autor (aunque negado), de las notas, las citas, además de las relaciones contextuales específicas mediante el uso de referencias externas al texto que aluden a la coyuntura o contingencia histórica.

3.3. Las conexiones literatura e historia. Al mismo tiempo que su alto rango de autorreflexividad, ya sabemos que otro de los rasgos de la poesía postvanguardista es la intensa relación de los textos literarios con los contextos históricos y extraverbales; en otras palabras, de la relación arte-vida: arte porque el texto se justifica en una tradición literaria culta, con procedimientos característicos propios de la transtextualidad, pero también de la retórica clásica como la ironía y la sátira; vida, porque sus alusiones y referencias remiten a la historia de Chile bajo la dictadura de Pinochet.

Los sonetos de Lope Sin Pega constituyen una crónica alternativa de los años de la dictadura militar, que abarcan desde la época de las primeras protestas masivas, el colapso económico posterior al boom económico de fines del 70 y principios de los 80, los sucesivos cambios de gabinete, la visita del Papa Juan Pablo II y la campaña del plebiscito de 1988, según las observaciones de Castillo. Son textos mordaces y patéticos sobre la contingencia socioeconómica y política durante los últimos años de la dictadura militar en Chile, que han ampliado su temática en la referencia a los avatares del período democrático posterior sin perder su ironía ni su gracia.

Su dimensión de crónica está indicada por el propio autor en el título de la primera sección de los sonetos de Lope, "Crónica parcial de Chile bajo la bota", y se refiere a los problemas más urgentes y terribles de la vida cotidiana del país y sus principales agentes. Sin duda, el tema central del conjunto lírico es la dictadura militar, expresado con la metáfora "bajo la bota" y desarrollado principalmente a través de aspectos económicos, comunicacionales, políticos y represivos.

Sobre los primeros hay diversos textos: algunos, como "Donde se habla de los sortilegios que mueven los últimos respiros de nuestra economía", "De cómo evolucionaban las noticias en el Chile del "Vamos bien, mañana mejor", "Donde se trata de la situación económica y de los empellones que le da el gobierno de EE.UU. empujándola cada día más cerca de la punta del cerro", se refieren a la macroeconomía del país y del modo que afecta a los ciudadanos: "Sin ni un cobre va toda nuestra gente,/ el hambre en fiera guerra los abate,/ al miserable estómago inocente/ USA y Reagan le han dado jaque mate" (p. 56). En cambio, otros remiten a personeros económicos del régimen, como los ministros Escobar que se transforma en escobilla porque "todo lo escobilla" (p. 55) o Cáceres (Cacerillo), pero sobre todo de los personajes que lucieron roles protagónicos: los Chicago boys. Estos economistas son mostrados como seres ambiciosos que viven fuera de la realidad ("Los años más felices de mi vida/ fueron vuelo y color de mariposa", p. 45), dependientes de las apariencias, el lujo y el dinero (“¿Qué fue de la amistad que me entregabas,/ Sheraton? ¿Qué fue de ti, fiel Cordillera?/ ¿Qué es de ti, viejísimo Carrera, que mi VISA y mi MASTER alababas?", p. 46), en última instancia del modelo económico que "hoy se nos fue a las pailas" (id.).

Los aspectos comunicacionales, elementos claves del nuevo sistema, aparecen caricaturizados mediante la hipérbole como múltiples "estelares, animadores y noticiarios de fantasía que acontecen en tevé", donde "llueven deportes, shows y teletones,/ Matas, Vodanovices, Don Franciscos,/ ciegos a la cultura, siempre ariscos,/ vendiendo circo y farsa por cajones" (p. 42). Aunque también habla de la evolución de las noticias, "De cómo los noticiosos fueron transformados en noticiarios, más tarde en noticieros, hasta llegar a los actuales noticeros", una fuerte crítica se hace al papel alienante de la televisión en "Breve noticia de lo que aparece y lo que no aparece en Tevé Nacional"; luego de una enumeración de deportistas, personajes de la farándula y paisajes, elementos que copan la pantalla, se observa que "Al arte, cero, cero a la cultura,/ salvo de artes marciales, puntapiés,/ y aplausos tras aplausos a la usura”. Sin embargo, las observaciones a los medios de comunicación apuntan a una referencia ética y axiológica a la fuerza de la verdad, que "como respira y aún no calla/ a muchos les asusta el calendario/ que ya cuenta sus días de mentira” (p. 49).

En cuanto a los elementos propiamente políticos y represivos, aparecen en especial en dos sonetos "con 
vocabulario de moda" que sugieren de modo irónico y satírico la situación de control, abuso y anulación de los derechos humanos en Chile. El primero se inicia con una parodia gramatical y léxica que reitera los términos más usados durante la dictadura:

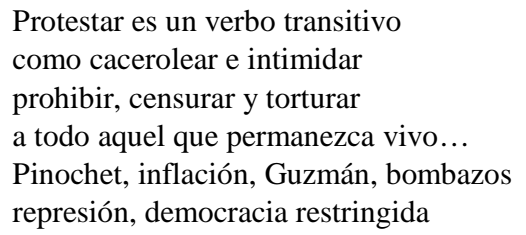

políticos soñando con volver

Importancia de metas, no de plazos miles soñando un plato de comida $y$ un eco que repite va a caer

(p. 62).

El segundo insiste en la enumeración de palabras claves que permiten denunciar la crisis política y global del país (degollados, torturados, golpeados, soplones, manoarmada, culebrones, rastreros, etc.), así como agentes e instituciones que apoyaban a la dictadura: CEMA, COANIL, Cardoen, un Gorila llamado Pinochet, SICAR, UDI, la Lucía, El Mercurio, "palabras de ayer y hoy, como una reja".

Junto con la denuncia y la crítica, aparecen sutilmente ciertas llamadas a la esperanza y al compromiso con la lucha liberadora. A veces el poeta se expresa metafóricamente, "Cuando se oyen soplar los nuevos vientos/ que a muchos les parece temporal" (p. 65), o alude a un paro nacional que dio la ilusión del debilitamiento del gobierno (p. 44), o asume una actitud combativa, "Si nos derrotan ganaremos cana/ y muchos pobres perderán la vida;/ ¿cómo volver al punto de partida,/ sin esperanza de vencer mañana?" (p. 52), la que enfatiza en los versos que siguen:

Cambio todo el ayer por el mañana; sin esperar sus señas a él acudo $\mathrm{y}$ lo veo rondar por mi ventana.
Pongo toda mi fuerza por escudo para oír del futuro la campana en este hoy que me mantiene mudo

(p. 73).

\section{CONCLUSIONES}

Lope Sin Pega es el sujeto central de una poesía postvanguardista que se deleita en la reiteración de los usos, ritmos y retóricas de la poesía barroca y manierista del Siglo de Oro español, que se reciclan para usarlos como estrategias de la lucha clandestina contra la dictadura militar mediante la resistencia cultural, sujeto marginal que actúa en la vida pública, que se disfraza, disimula y esconde (como los críticos de palacio que por medio de la sátira se burlaban de los gobernantes) y forma parte de la literatura de la resistencia chilena al fascismo mediante su escritura comprometida con la denuncia y las esperanzas de liberación.

Un personaje nuevo, pero escrito con textos viejos, Lope Sin Pega, personaje carnavalesco y achilenado en pleno siglo XX, cumple con los rasgos básicos del neomanierismo: la identificación con el personaje que autoriza la escritura, pero también se burla de ella y la parodia, el miedo a ser uno mismo por la represión que le hace disfrazarse de Lope, aunque asumiendo su ambigua identidad como una estrategia de resistencia político-cultural. Pero también asume la necesidad de ser o parecer otro como estrategia de denuncia y ocultamiento: transforma el nombre de Lope de Vega en Lope Sin Pega y su calificación, Fénix de los Ingenios, por Fénix de los Cesantes, fundándose en una situación social y autobiográfica.

Lope Sin Pega ha ampliado el sistema literario chileno por la vía de la construcción de la figura de un sujeto autor y hablante que se funde en un solo personaje con referencias intertextuales, autobiográficas y testimoniales de la contingencia, incluyendo un nuevo autor ficticio en la institución literaria. Las relaciones intertextuales permiten una comunicación privada, exclusiva, de complicidad, información restringida, mensajes en clave y lo autobiográfico asegura la presencia de un autor de la misma posición ideológica, es decir, que participa literariamente en la resistencia a la dictadura militar. En otras palabras, Lope Sin Pega usa estrategias que permiten enmascarar al poeta para desenmascarar al dictador.

\section{OBRAS CITADAS}

\subsection{Fuentes primarias}

Trujillo, Carlos Alberto. 1986. Los que no vemos debajo del agua. Santiago: Editorial Cambio.

Trujillo, Carlos Alberto (comp. y prólogo). 1999. No se engañe nadie, no. Lope Sin Pega. Santiago: Mosquito 
Comunicaciones. "Breves y opacas luces sobre la obra poética de Lope Sin Pega”, Prólogo. 5-24.

\subsection{Fuentes secundarias}

Carrasco, Iván. 1989. "Poesía chilena de la última década (1977-1987)”. Revista Chilena de Literatura 33: 31-46.

—_. "Poesía chilena en Chiloé: Carlos Alberto Trujillo". En Torres, Jorge. 1996: 57-74.

Castillo, Roberto. 1996. "Los versos amargos de Lope Sin Pega: de la poética del apagón a la crítica del encandilamiento". En Torres, Jorge 1996: 159-66.

—. Contratapa a Trujillo, Carlos Alberto (Comp. y Prólogo). 1999.

Coddou, Marcelo. 1996. "Entrevista de Marcelo Coddou a Carlos Trujillo”. En: Torres, Jorge 1996: 177-92.

Epple, Juan. 1996. "Gente de palabra. Carlos Trujillo y la obra cultural de Aumen”. En Torres, Jorge 1996: 197-211.

Galindo, Oscar. 2005. "Neomanierismo, minimalismo y neobarroco en la poesía chilena contemporánea". Estudios Filológicos 40: 79-54.

Lastra, Pedro. 1987. "Poesía hispanoamericana actual”. Relecturas hispanoamericanas. Santiago: Universitaria. 12937.

Torres, Jorge, ed. 1996. Por el territorio de los límites. Propuesta de Lectura de una Cierta Zona de la Poesía Chilena. Aproximaciones a la Poesía de Carlos Trujillo. Valdivia: Barba de Palo Ediciones.

Villegas, Juan. 1983. "Poesía chilena actual: censura y procedimientos poéticos”. Hispamérica 34-3: 145-154. 